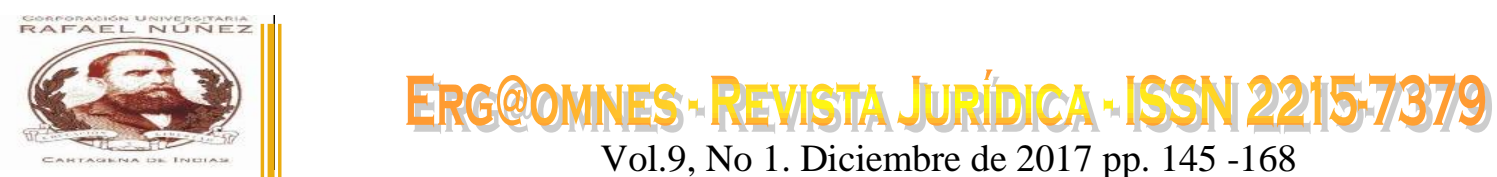

Vol.9, No 1. Diciembre de 2017 pp. $145-168$

Artículo Original

Recibido para publicación: Junio 16 de 2017

Aceptado para publicación: Octubre 16 de 2017

\title{
Elementos para la discusión sobre la gobernanza y gobernabilidad en el posconflicto en Colombia.
}

\section{Elements for the discussion on "governance" in the post-conflict situation in Colombia.}

\author{
Autor: Milton Buelvas Mendoza \\ Oscar Florez Campo ${ }^{2}$ \\ Correspondencia: myenbume@gmail.com
}

RESUMEN

En el presente artículo de reflexión se dará cuenta que el éxito del posconflicto concurren diversas variables que si se logran materializar permitirán reafirmar la paz y su permanencia en el tiempo. Podemos destacar entre esas variables, el cumplimiento de los Acuerdos pactados entre gobierno e insurgencia, y para eso se necesitará voluntad política de las partes, y los recursos económicos que sostengan lo acordado. Que la Justicia Especial para la Paz cumpla su cometido y logre garantizar justicia, reparación y no repetición. Estos aspectos significan que los gobernantes deben estar dispuestos a impulsar la cristalización de lo pactado y para ello será indispensable gobernanza y gobernabilidad.

\section{Palabras Claves:}

Posconflicto, pos acuerdos, Gobernanza, gobernabilidad, institucionalidad, posverdad, justicia, paz

\begin{abstract}
This reflection article will show the success of the post conflict many variables concur that if succeeding in materializing will allow reaffirming peace and its permanence in time. We can highlight among those variables, the fulfillment of the Agreements between the government and insurgency, and for which it will be require political will from both parts, and the economic resources that support what was agreed upon.That the Special Justice for Peace fulfills its mission and manages to guarantee reparation, justice and non-repetition. These aspects mean that the rulers must be willing to promote the crystallization of the agreement and for this it must be indispensable governance and governability.
\end{abstract}

\section{Keywords:}

Post-conflict, Post-agreements, Governance, Governability, Institutionality, Post-truth, Justice, Peace.

\footnotetext{
${ }^{1}$ Abogado. Especialista en Seguridad Social y en Derecho Administrativo. Candidato a Magíster en derecho. Líder del Grupo Derecho Público de la Facultad de Ciencias Sociales y Humanas - Corporación Universitaria Rafael Núñez. Línea de investigación DESC - Eje de Gobernabilidad Democrática. E-mail: myenbume@gmail.com

${ }^{2}$ Estudiante de V semestre del Programa de Derecho de la Corporación Universitaria Rafael Núñez, sede Cartagena.
} 


\section{Introducción}

Sin duda, un elemento que hace distinto a todo el proceso que se vive en Colombia es haber involucrado tres elementos indispensables para llegar a buen puerto: Justica, reparación y garantías de no repetición. Pero no basta. En todo posconflicto será muy importante que los gobiernos que estén al lado de la culminación óptima del posconflicto puedan desarrollar gobernanza y gobernabilidad.

Habría que preguntarse ¿cuáles son las transformaciones que el país debe adelantar para alcanzar el éxito del posconflicto o posacuerdos? ¿Qué debe hacerse para garantizar la gobernabilidad en el posconflicto? Hay que garantizar el monopolio de las armas en manos del Estado, elevación de los indicadores de bienestar de la población y transformar las instituciones formales representativas para su relegitimación y cambio de hábitos de pensamiento.

Por simples razones de presentación nos referiremos a los temas aquí planteados de manera parcelada, pero en toda la exposición está inmersa la relación gobernanza, gobernabilidad y posconflicto. Si tenemos meridiana claridad sobre los conceptos de gobernanza y gobernabilidad, entenderemos mucho mejor su importancia en el posconflicto.

\section{Metodología.}

La metodología empleada en esta investigación fue de naturaleza jurídica, orientada bajo el enfoque de Tipo Cualitativo, y de tipo exploratorio, aproximándose a estructuras teóricas y fenomenológicas, teniendo como área de trabajo el país y la discusión que suscita la temática tratada. Además bibliográfico, lo que responde a la 
recolección de información, con base en textos de actualidad jurídico-político y el análisis sistemático, bajo parámetros de exploración rigurosa.

\section{Materiales e instrumentos de recolección de la información.}

Dado que el diseño metodológico es de carácter bibliográfico, se recurrió en consecuencia a las fuentes secundarias que nutrieron y dieron contenido al presente producto, indagando en textos jurídicos, políticos, históricos, epistemológicos y filosóficos, buscando la información necesaria y pertinente que sirvieron al problema de investigación.

\section{Plan de análisis de los datos.}

La comprensión, el análisis y la producción de textos jurídico-políticos y filosóficos, se hará bajo parámetros de interpretación sistemática, lógico, racional de los textos.

\section{Unidad de análisis.}

Esta Investigación, en la medida en que es exploratoria, trabajará con las siguientes unidades de análisis:

Actores Políticos: Los actores políticos y administración del sector Estatal, la FARCEP firmantes y participantes del acuerdo y su ejecución

Actores Académicos: La Academia es un actor que históricamente ha sido muy activa en los procesos o movimientos de fomento de la busq ueda de la paz mediante negociación política entre los insurgentes y el Estado en Colombia. No obstante, para efectos de esta investigación solo se tomará como Unidades de Análisis una muestra de expertos tomaron de las Universidades y centros de 
pensamiento e investigación relacionados con la negociación y el cumplimiento del acuerdo.

Sociedad Civil: La sociedad y los líderes de los grupos sociales juegan un papel importante en cuanto a los procesos de vigilancia, control y sanción social del cumplimiento de las partes al texto del acuerdo. Para esta investigación fue importante consultar la visión, la perspectiva de sectores representativos de la Sociedad Civil mediante los pronunciamientos y documentos producidos ya como víctimas, desplazados o comunidad en general.

\section{Resultados y discusiones.}

\section{Sobre gobernanza y gobernabilidad en el postconflicto.}

\section{Gobernanza}

El diálogo, la acción colectiva, la importancia de la participación desde lo democrático, identificando las necesidades e intereses de la sociedad, de identificar los intereses de los ciudadanos, la interconexión del territorio, ciudadanos, políticas públicas y ética, es uno de los grandes retos de la gobernanza.

En los últimos años el término gobernanza tiene un gran espacio en la sociedad académica y política. No obstante en muchos casos se utiliza como sinónimo de gobernabilidad, como buen gobierno y no es por ahí el asunto.

Tres elementos, tres indicadores importantes miden la gobernanza: efectividad, eficiencia y duración. Ser eficiente es el producto de la relación entre los recursos utilizados en un proyecto y los logros conseguidos con el mismo. Se es eficiente cuando se utilizan menos recursos para lograr un mismo objetivo. Por su parte la 
eficacia se refiere a los niveles de consecución de metas y objetivos, es decir, nuestra capacidad para lograr lo que nos proponemos. La gobernanza tiene como fundamento la equidad, la participación, el pluralismo, la transparencia, la responsabilidad y el funcionamiento del Estado de derecho.

Desde una visión que parte del Estado, la gobernanza es el arte de liderazgo público, en el cual el protagonista excluyente es el Estado. Lo que significa el régimen, la gestión pública, y la capacidad de gobernar hacen parte de las variables necesarias para una óptima gobernanza. Para Guy Peters (2003), quien es uno de los que representa esa visión y que tiene al Estado como el núcleo de la gobernanza, esta con lleva "proveer una dirección coherente a la sociedad y que ésta es una función del Estado, independientemente de los cambios en las estructuras de gobierno promovidas por la descentralización y democratización". Peters considera que los Estados-Nación, sus gobiernos, desempeñan un papel central y dominante en cuanto a la forma de gobernanza que asumen.

De otra parte, la visión policéntrica recurre a otras ciencias que vienen en su ayuda para alcanzar un postura conceptual acerca de la gobernanza, toma mano de la sociología, la antropología, la psicología social, la ciencia política para indicar que la gobernanza emerge del Estado, la sociedad civil y el sector privado pero con funciones distintas. Para Putnam una sociedad civil fuerte garantiza buena gobernanza, pero Manuel Castells (2002) considera que la gobernanza "es un juego de poder, en el cual la competencia de intereses, el conflicto y la negociación son elementos básicos", y para quienes pregonan un mundo globalizado y por tanto la gobernanza global, es la institucionalidad global la que es protagónica, tal es el caso de algunos de los teóricos de la globalización y de la gobernanza global; por ejemplo el trabajo de Cable Keohane y Held 2002, (1995). 
Para decirlo de manera elemental, cuando se gobierna intervienen tanto quienes gobiernan como los gobernados, cómo se relacionan y cómo toman decisiones es lo que conocemos como gobernanza.

La Gobernanza son "las interacciones y acuerdos entre gobernantes y gobernados, para generar oportunidades y solucionar los problemas de los ciudadanos, y para construir las instituciones y normas necesarias para generar esos cambios", es según Pablo Chirif (2016) "...una suma de gobierno y confianza. Es el estilo de funcionamiento de una sociedad.". Es evidente suponer el peso específico que alcanzara la gobernanza en el posconflicto.

Lo anterior trae consigo que la ciudadanía participe en las decisiones que le permitan una vida donde el mínimo vital para hablar en términos jurídicos, esté resuelto. Se requiere que exista libertad de expresión, respeto por los derechos humanos, libre asociación, que no exista asimetría en la información y conozcan qué hacen sus gobiernos, pero mucho más allá del ritual de las rendiciones de cuentas.

Quienes gobiernan deben estar en capacidad de cumplir sus funciones y satisfacer las "demandas societales" al decir de Camou (1995).

La conceptualización que se ha tenido tradicionalmente sobre Gobernanza, ha venido sufriendo transformaciones, cambios, para bien o para mal. Pasamos de forma rápida de un mundo bipolar, a un archipiélago de poderes, se afianzó la globalización, surgieron con fuerza instituciones conocidas como organizaciones no Gubernamentales, los avances tecnológicos han sido innovadores, la llamada sociedad civil es hoy más participativo así recurra al ensayo y error en la búsqueda de su propio destino, lo que ha traído consigo que el Estadio debe adecuarse a esos cambios a riesgo de deteriorarse y deslegitimarse. 
A un Estado deslegitimado le es imposible desarrollar procesos de paz y mucho menos consolidar posconflictos, pues está invalidado por la sociedad.

La gobernanza tiene un rol compuesto por distintas funciones: regula las políticas públicas en lo referente al ámbito político, económico y social, debe ser instrumento de renovación de los fundamentos democráticos de la Nación y debe propiciar la renovación de los espacios de la vida política.

De un lado se presenta como un nuevo motor de la regulación política, social y económica del nivel local al nivel global y una herramienta de renovación del espacio político y de los fundamentos democráticos de nuestras sociedades.

Como hay necesidad de medirlo todo, hay un indicador llamado Índice de gobernanza mundial (IGB) que sigue en proceso de construcción, que tiene lo siguientes componentes para evaluación: paz y seguridad, desarrollo humano, desarrollo sustentable, Estado de derecho, derechos humanos y participación.

Necesariamente los gobiernos son protagonistas en la gobernanza, (governance), pero en el campo, por ejemplo, son influyentes en la toma de decisiones, los propietarios, los tenedores de las tierras, las organizaciones de los campesinos cooperativas agrícolas, ganaderas, ONG, los institutos de investigación, los líderes religiosos, gremiales, las Fuerzas Armadas, la policía, la delincuencia, bandas criminales, grupos generadores de violencia; pero también son influyentes al momento de las decisiones, los medios de comunicación, Agencias internacionales de Desarrollo, multinacionales.

Sin embargo, en la toma de decisiones, pueden aparecer actores informales, que fungen de lobistas, que se hacen voceros, reales o ficticios, de quienes deben decidir y terminan "capturando" esas decisiones en beneficio de quienes necesita 
satisfacer sus intereses particulares. ¡La gobernanza también puede ser apropiada en beneficio propio!

\section{Gobernabilidad}

La gobernabilidad es "un estado de equilibrio dinámico entre el nivel de las demandas societales y la capacidad del sistema político, Estado-gobierno para responderlas de manera legítima y eficaz" así lo enseña Antonio Camou (1995, ob. Cit.) lo que conlleva en sí mismo lograr algunos acuerdos con los gobernantes: rol del Estado, y políticas públicas, reglas institucionales.

En palabras de Kant (2003), necesitamos un Acuerdo de Mínimos, que en democracias sin apellidos, esos acuerdos mínimos se plasman en la Constitución de cada país. Es imposible llegar a acuerdos si cada quien desea que se acepten los máximos del otro, Máximos ideológicos, políticos, económicos, de creencias de fe, morales. La gobernabilidad está íntimamente ligada a cómo se gobierna. Nada tiene que ver con la distribución burocrática o la contratación pública, como lo creen muchos políticos que desvirtuaron el concepto. .

El salvadoreños Ricardo Córdova Macías (1995), en el Documento de Trabajo llamado El Salvador en transición: el proceso de paz, las elecciones generales de 1994 y los retos de la Gobernabilidad democrática, relaciona la gobernabilidad a la ampliación, profundización y consolidación de la democracia para lo cual es necesario superar la polarización, una forma establecida en Colombia para atravesársele al proceso de paz incluido los Acuerdos, ha sido la estrategia de crispar a la sociedad, de agudizar la polarización; hay que avanzar en los procesos de concertación, hasta donde sea posible, sin que estos sean paralizantes, asumir las necesidades de los empobrecidos, donde políticas asistencialistas no sean la esencia de los programas, ampliar canales participativos, someter, controlar la delincuencia, libertad a la oposición para 
actuar dentro del orden institucional, establecer mecanismos civiles de concienciación frente a las demandas de la sociedad y consolidar la institucionalización jurídica.

Es conveniente señalar aquí el relacionamiento lleno de tensiones entre gobernabilidad y democracia, pues no necesariamente van de la mano o el uno depende del otro para su existencia. Es claro que gobernabilidad sin democracia es generador de autoritarismo, así sea un gobierno eficaz y eficiente. Pero tener democracia sin mayor gobernabilidad puede producir inestabilidad política. Ejemplos abundan en la Latinoamérica de hoy y la de siempre.

Estudiosos del tema como Camou (1995) han reflexionado "en torno a la gobernabilidad democrática y a la democracia gobernable.", es decir, que vayan de la mano los procesos democráticos con el fin que surjan gobiernos legítimos y ejercicio eficiente de los gobiernos que se legitiman frente a la solución de las "demandas societales".

Hoy el desafió, entre tantos vigentes, consiste en que haya gobiernos democráticos que propicien que la democracia sea el ámbito por excelencia donde se diriman de forma pacífica las confrontaciones de toda naturaleza que aparezcan en la sociedad. Debe ser una relación de doble influencia entre gobernabilidad y democracia, que posibiliten gobiernos democráticos y a la vez que estos sean legítimos, eficaces, eficientes, prístinos.

Sobre este tema, el finado Giovanni Sartori (1989) viene en nuestra ayuda y se plantea algunos interrogantes que cada país debe resolver "...porque sólo sabiendo qué es la democracia, en qué consiste, cuáles son sus valores, pilares y fundamentos, sabremos qué podemos esperar de ella". 
En los momentos actuales que aún no se ha consolidado el período especial del posconflicto, Sartori: nos recuerda que "sin el marco político democrático no puede haber ni democracia social ni democracia económica". ¡Tengámoslo en cuenta!

De otro lado, el PhD. en Ciencias políticas, Selwyn Ryan (2004), considera en Dimensión Política del Desarrollo Humano que la gobernabilidad debe ir más allá del concepto de democracia, ya que debe existir un modelo excelente de gestión pública, administrativo y financiero que traiga consigo un gran desarrollo de la transparencia y las buenas maneras de gerencia en asuntos públicos.

Es muy importante precisar otro aspecto de la gobernabilidad, que parte desde una mirada económica. Lo que se conoce tradicionalmente como capital humano es un elemento muy relevante para impulsar el desarrollo social de una Nación. Si se convierte en imperativo la necesidad de invertir en capital humano, este llegará a ser un gran estímulo para el crecimiento y factor necesario si hay decisión política, para disminuir las inequidades.

Por capital humano entendemos el conocimiento, las habilidades del componente laboral en sentido estricto y el del componente ciudadano en sentido amplio, este concepto está ligado al de buen gobierno. Según Williamson (2005) la gobernabilidad no es más que definir e imponer reglas claras con el fin que los contratos, los acuerdos, los pactos, se cumplan. Es en su criterio "modos institucionales alternativos para organizar las transacciones" o, es "la matriz institucional dentro de la cual las transacciones son negociadas y ejecutadas".

Si entendemos la transacción como la unidad que la conforman tres elementos a saber: conflicto, orden y reciprocidad la gobernabilidad es un esfuerzo por disminuir el conflicto e impulsar el orden. 
Juan Rial (1987) enseña que la Gobernabilidad es "la capacidad de las instituciones y movimientos de avanzar hacia objetivos definidos de acuerdo con su propia actividad, y de movilizar con bastante coherencia las energías de sus integrantes para proseguir esas metas previamente definidas. Lo importante no es si se es gobernado o si se gobierna, sino "cómo" se hace".

Para abreviar, hay que decir que la Gobernabilidad se ha llenado de matices diversos: eficacia, buen gobierno, estabilidad... Pero sobre la gobernabilidad hay tres elementos que le pueden generar crisis, al decir de Habermas, Huntington y Connor (1981), sobrecarga y crisis fiscal del Estado, crisis de la democracia y Crisis de la Racionalidad. ¡Como para no olvidar!

\section{Posconflicto}

Los procesos de paz, sus posconflictos han dejado estelas de fracasos, de éxitos, y de allí muchas experiencias, muchas lecciones.

Los conflictos donde se recurre a la violencia armada y diferentes tácticas de guerra en cada país, dejan profunda huellas de horror, de dolor, de sentimientos de odios por parte y parte, inestabilidad social, económica y política y aplaza indefinidamente la solución a los graves problemas de miseria, pobreza, inequidades, instituciones débiles y deslegitimadas, corrupción y rezago del aparato productivo, infraestructural, logístico, educativo, corrupción...

Es por ello que detener la guerra para siempre debe abrir nuevas prospectivas y encaminar a las naciones, a los Estados, a los gobiernos, a la ciudadanía a la solución de los problemas que los afectan mediante los senderos institucionales.

En medio de los conflictos armados, el argumento principal para no superar la pobreza y satisfacer las necesidades de la población, es que los recursos 
estatales se dirigen a garantizar la seguridad y combatir la criminalidad en sus diferentes manifestaciones.

Una vez se logran los acuerdos y se inician los posconflictos, los pobladores se llenan de escepticismos pero también de expectativas en que todo mejorará. Para lograr el cumplimiento de esas expectativas se requiere un mejor ciudadano sin duda alguna, más involucrado en los temas nacionales, con una mayor cultura política, vencer la baja estima colectiva, y entender que por medio de lo institucional puede hacer un país más amigable menos hostil, una mejor Nación.

Tener conciencia sobre su responsabilidad en el posconflicto, para no dejarla solo en manos de los gobiernos o de los políticos, o de quienes pactaron los Acuerdos. Es necesario el avanzar ciudadano en estos aspectos y no ser "apresados" por la posverdad como lo veremos. Es de esta manera como se puede lograr que esas expectativas creadas por el fin de la guerra, no se conviertan en una nueva frustración colectiva donde todos perdamos.

Todos debemos entender, como está demostrado por la historia reciente y basta ver la experiencia Centroamericana, que los posconflictos no son cuestión de meses o años, son procesos de décadas, pues se requieren cambios en las instituciones formales y transformaciones en los hábitos de pensamiento. Para decirlo con Hegel (1985) "hay que hacer el esfuerzo por salir de la inmediatez de la vida sustancial".

No es suficiente dejar las armas, se trata de desmovilizar a la Nación de tanta violencia de toda naturaleza que ha archivado a través de los tiempos en todos los escenarios. Las cadenas de no valores, como la intolerancia, el no respeto por la opinión ajena, lo que no significa eliminar la controversia por ejemplo, generan un ambiente nocivo para ir armonizando la paz, lo que se agrava si hay agentes que aúpan odios. Sería retórica hueca si decimos que estamos por apoyar los 
acuerdos, el período del posconflicto pero excluimos a las personas por su raza, credo de fe, sexo, género, opción sexual, ideología, educación, etc.

Un reto que aún no se ve superado en el momento que vivimos es la estrategia de comunicaciones que lleve al ciudadano a apersonarse del posconflicto. Parece que estuviese a cargo, bajo la responsabilidad de otros. Que termine la guerra no nos lleva de manera mecánica a la consolidación de la paz. Esa ley histórica no existe. Ya tenemos experiencia sobre estrategias de comunicación erradas y otras exitosas así sea que hayan acudido a la posverdad.

Es necesario que la Nación entienda que debe hacer suyo el tiempo en que vivimos para dejar atrás los horrores de un conflicto que nos laceró y torturó por interminables décadas, y no devolvernos a la tragedia de la guerra y la muerte. Si cada nacional no ve en su realidad diaria los beneficios del fin de la guerra, perderá apoyo y la incertidumbre vendrá acompañada de frustración poniendo en peligro lo alcanzado. El posconflicto no puede beneficiar solo a los actores de la guerra si no a la sociedad entera.

El programa del posconflicto se diseña, elabora, se construye, de abajo arriba, de arriba abajo, de lo elemental a lo complejo y viceversa, desde el Centro y desde las regiones, desde las regiones hacia el Centro, desde el campo a la ciudad y de la ciudad al campo, desde las zonas más afectadas por el conflicto armado y en aquellas donde no hubo conflicto, desde municipios y veredas.... En esto nadie tiene la última experticia. Pero hay que materializar todo lo acordado e ir más allá.

En este "período de gracia" que nos deja el fin del conflicto con uno de sus principales actores, por supuesto que temas económicos, estructurales, instituciones, son muy importantes. Pero hay un elemento terrible que destruye a la nacionalidad y a las instituciones, la corrupción, que no hay que mirarla como un 
caso solo para la justicia. No. Los actos venales, incrementan la desconfianza, desprestigian a las instituciones formales, minan la gobernanza y la gobernabilidad y socavan las estructuras del Estado, con todo el peso que ello significa.

Por muchísimos años y tal vez dos centurias, se ha diseñado un "modelo de gestión pública" que facilita y propicia la apropiación del Estado por particulares en su propio beneficio. Es mucho más ambicioso que ser rent seeking, como señala, Gordon Tullock (1967), pues estos buscan capturar rentas económicas a partir de la utilización de las relaciones políticas, económicas abandonando la producción de valores añadidos por actividades económicas de libre competencia sin el uso de variables perversas que distorsione la contratación, los negocios legítimos con el Estado.

En un marco referencial como el descrito será más difícil llevar a buen término un posconflicto con una gobernanza y gobernabilidad precarias. En la medida que más se ponen barreras para que no se burle la transparencia, por ejemplo, aparecen los atajos que permiten saltar barreras y a la vez incrementan las alcabalas.

Ningún proceso exitoso de posconflicto ha sido posible sin consensos, no se trata de unanimismos, pero sí de consensuar con las mayorías los aspectos mínimos para sacar adelante un proceso largo y sinuoso. Es de esperar que la política cambie a pesar del escepticismo, surgirán nuevos actores, propuestas posiblemente renovadas y un mejor ciudadano. Un Estado nacional fuerte. $Y$ un mercado que deje de ser el todopoderosos que todo lo regula, supuestamente inteligente, que supuestamente puede autorregularse, y tampoco se necesita un mercado intervenido permanentemente que lo ata, lo hace desaparecer.

De los 1.122 municipios que según el DANE (2016) tiene Colombia, el 85 por ciento, unos 954, gastan un poco más del 50 por ciento en gastos de 
funcionamiento, así lo demuestran estudios del Ministerio de Hacienda. En el posconflicto así su financiación esté a cargo del Gobierno central, los municipios deben propiciar las mínimas condiciones al menos, para apoyar los procesos del posconflicto en materia de verdad, justicia y reparación a víctimas directas e indirectas de la irracionalidad de la guerra.

Además de los retos propios del cumplimiento de los Acuerdos de paz, en el posconflicto es muy posible que haya que lidiar con graves problemas de inseguridad de bandas delincuenciales dedicadas desde de hurto, atracos callejeros, pasando por tráfico ilegal de drogas ilícitas, minería ilegal, hasta homicidios. Se requiere Gobernanza, es decir, acuerdos entre Estado y Nación que posibiliten la generación de oportunidades, satisfacer necesidades de los pobladores y fortalecer o constituir las instituciones formales que se requieran para producir las transformaciones inaplazables. ¡Se necesita Gobernanza!

El posconflicto requiere un Estado eficaz y eficiente, necesita gobernabilidad y necesita el cumplimiento de otras tareas: desactivar la "justicia privada", violencia intrafamiliar, todo aquello que afecte la convivencia, el abandono de menores, la discriminación, los cultivos de origen ilícito, la destrucción del ambiente, para citar solo esos ejemplos. Tareas desmesuradas como estas no será posible, con una sociedad abandónica, abúlica frente a los problemas nacionales. Necesitamos para asumir el posconflicto, gobiernos con alta gobernabilidad, cuya eficacia no esté en discusión.

La Constitución que hoy nos rige, profundizó la descentralización en Colombia y estableció en nuestro país un Estado Social de Derecho, como lo dice el Artículo 10. Colombia es un Estado social de derecho, organizado en forma de República unitaria, descentralizada, con autonomía de sus entidades territoriales, democrática, participativa y pluralista, fundada en el respeto de la dignidad 
humana, en el trabajo y la solidaridad de las personas que la integran y en la prevalencia del interés general.

Eso significa que el carácter unitario del Estado encierra por mandato constitucional que protección, gestión de necesidades y demandas de la sociedad por derechos, libertades individuales, públicas se deben atender de forma armónica entre autoridades nacionales y locales.

Es importantísimo resaltar que las entidades locales por disposición constitucional deben elaborar y ejecutar planes de desarrollo teniendo en cuentas prioridades de los municipios y los recursos fiscales y financieros. La aplicación de los acuerdos en la jurisdicción que corresponda debe estar asegurada por la vía de los recursos económicos, la voluntad política y consignada en los Planes de desarrollo ya mencionados.

Una de las dificultades que tienen los procesos de posconflicto es que abren la posibilidad de un aumento vertiginoso de seguridad urbana, lo que trae consigo no solo miedo, desconfianza, sino que puede aumentar los rechazos a los Acuerdos de paz, al endosarles a los desmovilizados esa situación de inseguridad.

Al referirnos al posconflicto es imposible hacerlo sin hacer referencia a la Jurisdicción Especial para la Paz (JEP) que tendrá funciones judiciales y es integrante del Sistema Integral de Verdad, Justicia, Reparación y No Repetición.

La JEP tendrá bajo su responsabilidad investigar, esclarecer, perseguir, juzgar y sancionar tanto las graves violaciones a los derechos humanos como al Derecho Internacional Humanitario (DIH) que se produjeron por causa atribuible al conflicto armado interno. 
Tiene la enorme responsabilidad la JEP de satisfacer el derecho de las víctimas a la justicia, contribuir a la reparación de las víctimas, a luchar contra la impunidad, al logro de una paz estable y duradera, brindar plena seguridad jurídica a quienes juzgue, ofrecer verdad a la sociedad colombiana.

Los magistrados de la JEP serán seleccionados por un Comité de Escogencia (www.comitedeescogencia.com), funcionará por 15 años mínimos, no puede haber extradición. Los guerrilleros desmovilizados podrán participar en política, los beneficios de la Jurisdicción especial para la paz serán aplicables a los miembros de las Fuerzas Armadas, los miembros desmovilizados de la guerrilla podrán ser funcionarios y contratar con el Estado, la responsabilidad no se podrá fundar sólo en la jerarquía del imputado y las sanciones serán las acordadas en los Acuerdos para los sanciones aplicables a los guerrilleros desmovilizados.

La gestión de la política pública posconflicto, debería ser entendida como una cadena de valor, agregación de valía en los procesos de dirección pública, que se materializan en procesos de concertación para brindar servicios y bienes de calidad a pobladores, y las cadenas de valor de seguridad y convivencia deben operar de acuerdo a los resultados no a las intenciones.

En los posconflictos las comunicaciones reales y diáfanas son de gran valor. La ciudadanía se muestra desconfiada de la información que recibe a través de los medios tradicionales, y es más proclive a alinearse al lado de la información que recibe por medio de las redes sociales., a sabiendas o no que lo que circula por esas redes muchísimas veces está lejos de la realidad. Hay incertidumbres a corto y mediano plazo que no sabemos cómo serán resueltas. $Y$ esa circunstancia involucra también al posconflicto. Los gobiernos necesitan redefinir su comunicación y acompañar sus palabras con hechos, pues no de otra manera podrá ganarse la confianza ciudadana. 
Aparecen reinantes las posverdades, que no acuden a los hechos racionales, reales, sino que estimulan decisiones emocionales, que recurren a repetir mentiras con ropaje de verdad para que las personas tomen decisiones con indignación. Lo que es lo mismo, para que tomen decisiones partiendo de sus emociones.

La posverdad es el punto final a un período de racionalidades, que hoy se trastoca en tiempos en que los iluminados, los que llenos de pasión y emociones definen el mundo de tus creencias. Hace muy poco tiempo The Economist (marzo 2017) le dedicó su artículo más importante a este tema titulándolo "Art of the Lie. Post-Truth Politics in the Age of Social Media"-"El arte de la mentira. La política de la posverdad en la era de los medios sociales".

Después de todo, los tecnócratas y los populistas tienen algo en común y es su aversión al debate: unos, porque poseen la única solución racional para cada problema; y los otros, porque sólo ellos expresan la voz del pueblo".

Estamos en Posconflicto, Posverdades, ¿estamos en Posdemocracia? Norberto Bobbio (1995) enseña que la democracia se caracteriza por poseer "un conjunto de reglas, primarias y fundamentales, que establecen quién está autorizado a tomar las decisiones colectivas y bajo qué procedimientos". Pero sigue señalando el autor mencionado que esas reglas tienen valores que vienen desde la Revolución francesa que a la vez legitiman y sustentan esas reglas, y avanzan más allá del sufragio universal y el principio de mayoría y minorías, la libertad y la igualdad, la solución pacífica de las controversias, para resaltar en ahora que estamos en posconflicto, el entendimiento en la disimilitud, o como dice Habermas, la comunicación puede servir para que sepamos en que consiste el disenso. 
El posconflicto se fundamenta en justicia, democracia y seguridad. Es decir, se debe garantizar los plenos derechos a las víctimas, nuevo diseño institucional para reducir las inequidades, acabar con la pobreza extrema, educación, equidad, nuevo tejido social, hacer sostenible el fin del conflicto armado, garantía de no repetición, fundamentar las bases para el crecimiento económico y el desarrollo social del país, mejoramiento de la capacidad de las Fuerzas Armadas para garantizar la protección ciudadana, combatir otras formas de violencia antidrogas, articular instituciones y entidades públicas entre sí, lograr territorios libres de minas antipersonal, política estratégica frente al cultivo de drogas ilícitas, minería ilegal, lo que constituirá la prueba ácida al posconflicto pues del éxito de al menos estas políticas, dependerá el fortalecimiento y la irreversibilidad del posconflicto.

El programa del gobierno nacional denominado Convivencia y Seguridad debería afianzar la transición de la guerra al posconflicto también combatiendo la delincuencia de distinta índole en campos y ciudades. Fortalecimiento de la administración de justicia, la capacidad investigativa en contra del crimen, la criminalidad. El Registro Único de Víctimas del Gobierno hasta 2017 establece 8.405.265 víctimas del conflicto, el desplazamiento forzado contribuye con un 86 por ciento. Así ha sido la desmesura de la tragedia nacional.

Los desplazados son una población altamente vulnerable a los cuales hay que garantizarles indemnización, restitución de tierras, vivienda, reparación colectiva, como construcción de infraestructura y reconstrucción de infraestructura social, asistencia psicosocial, programas de retorno a su sitio de origen, intervenir los eslabones de la cadena de las drogas ilícitas: de diseño, heroína, cocaína y similares.

Por último, es válido preguntarse ¿cuánto valdría y cómo se financiaría el posconflicto? Hay quienes consideran que los beneficios del posconflicto ya se obtuvieron y se prueba con el crecimiento económico del país, a pesar de su 
desaceleración y los problemas del vecindario incluido el norte de América. La economía colombiana no está en crisis a pesar del modestísimo crecimiento del PIB del 2.0 por ciento en 2016, y del 3.1 por ciento en 2015.

Sin duda, que este posconflicto debe traer consigo enormes transformaciones nacionales, avanzar en los aspectos democráticos que nos permitan superar los rezagos que en esa área también padece el país, pero nada de este posconflicto será a título de gratuidad, ni el resto del planeta pondrá los recursos económicos para completar la misión.

En las cuentas del Gobierno indican que el posconflicto en un período de diez años costaría 90 billones de pesos solo para desarrollo agropecuario, jurisdicción agraria, formalización y registro de la propiedad rural, eficiencia tributaria y gobernabilidad local.

Pero no hay una cifra aún clara, pues entidades como Raddar (2017), creen que puede costar 240 billones por diez años, pero incluyendo los costos de militares, excombatientes, reparación de víctimas y restitución de tierras. Para el Ministerio de hacienda hay que invertir entre el uno y dos puntos del PIB cada año. Sin embargo aproximadamente el 80 por ciento de los costos los asumirá el Gobierno nacional y la Nación y el restante 20 por ciento vendrá de la cooperación internacional y el sector privado.

Esos recursos de la Nación vendrán vía endeudamiento interno y externo, reducir la evasión y la elusión e incremento de impuestos como se viene realizando. Las naciones que han padecido conflictos internos armados por mucho tiempo, quedan divididas, destrozadas, en las estructuras que sostienen lo público.

Es a partir de allí que en los procesos de post acuerdos de paz, de posconflictos exigen transformaciones esenciales en materia de gobernabilidad y 
gobernanza, para avanzar hacia una, nada fácil, Política Pública de Reconciliación Social.

El posconflicto, ese período de tiempo que viene después de superar de manera parcial o total, un conflicto armado, podría visualizarse con la virtud única de disminuir de manera significativa los indicadores de homicidios causados por el conflicto armado interno.

El posconflicto está acompañado del desarme, desmovilización, reintegración de los excombatientes, la reconciliación, la eficaz atención a los sectores vulnerables, la elaboración de Memoria y Verdad, justicia transicional, la reparación, estabilización política...

Esto no será posible sin el cumplimiento de las demandas que exigen los acuerdos y sin la eficacia y la eficiencia de los gobiernos nacionales y regionales y locales en la cristalización de esos Acuerdos, para decirlo en una frase, se requiere Gobernanza y gobernabilidad.

\section{Conclusiones}

La academia, la política y la sociedad civil debemos comprometernos a continuar un debate sereno, consciente y colectivo sobre la gobernanza y la gobernabilidad necesarias en el posconflicto para el cumplimiento de los acuerdos con la guerrilla de la FARC-EP

El país debe asumir en todos sus niveles y sectores un profundo debate sobre la institucionalidad necesaria para el cumplimiento de los acuerdos entre el Estado Colombiano y la insurgencia dela FARC-EP. 
El Estado Colombiano comprometido con la firma del acuerdo deberá garantizar la gobernanza necesaria para la relación con sus gobernados en el postconflicto

La gobernabilidad que se requiere para la formulación y aplicación de las diversas políticas públicas para la construcción de una paz estable y duradera es responsabilidad de todos los sectores políticos en cumplimiento del mandato constitucional, según el cual, "la paz es un derecho y un deber de obligatorio cumplimiento".

El período de transición entre el conflicto armado interno y la paz estable y duradera, denominado posconflicto o postacuerdo requiere de una visión de largo plazo, de nuevas mentalidades y de creativa institucionalidad, púes la actual estructura del Estado Colombiano despierta mucha desconfianza en la sociedad.

\section{Referencias.}

Bobbio Norberto. (1984) El Futuro de la Democracia. Editorial FCE México, 1986.

Bobbio-Matteucci-Pasquino; (1995) Diccionario de Política; Tomo I; Ed. Siglo XXI, 9a , Madrid,

Camou Antonio. (1995.) Gobernabilidad y democracia. Cuadernos del Instituto Federal Electoral (IFE) de México. Primera Edición, Septiembre de

Carvajal Martínez, Jorge Enrique, \& Guzmán Rincón, Andrés Mauricio. (2017). Economía de mercado y democracia: elementos para una crítica al discurso del desarrollo promovido por las Instituciones Financieras Internacionales. Justicia, (31), 116-134. https://dx.doi.org/10.17081/just.22.31.2602 
Cialti, Pierre-Henri. (2016). La mayor representatividad sindical en España*. Justicia, (30), 17-31. https://dx.doi.org/10.17081/just.21.30.1347

Constitución Política de Colombia. Edición Conmemorativa 1810-2010. Editorial Legis, Primera Edición. Bogotá D. C., 2010

Cárdenas, L. (2013). Prácticas de lectura y escritura en la universidad. ¿Qué y cómo leen y escriben los estudiantes de licenciaturas? Revista Amauta, 21, 139-162

Cruz, E. (2015). la Ciudadanía ECológiCa En aBya-yala/ amériCa latina. Amauta, 87-103.

DANE. Boletines periódicos.

Emmanuel Kant, (2003.) La paz perpetua. Biblioteca Virtual Universal www.ellibrototal.com.

Guy Peters (2003),El Nuevo Institucionalismo. Editorial Gedisa. Barcelona, España.

H. W. Hegel. Fenomenología del Espíritu. Editorial fondo de Cultura económica. Sexta reimpresión. México 1985.

Habermas, Huntington y Connor, sobrecarga y crisis fiscal del Estado. Editorial Península. Barcelona, 1981.

Habermas, Jurguen Teoría de la Acción Comunicativa. Editorial Santillana. Bogotá D. c., 1999. 
Manuel Castells. El estado del bienestar y la sociedad de la información. Alianza Editorial. 2002

Mejía Cáez, Miguel Ramón. (2017). El derecho internacional de los derechos humanos, un nuevo concepto. Justicia, (32), 38-63. https://dx.doi.org/10.17081/just.23.32.2904

Pabón Arrieta, Juan Antonio, \& Torres Argüelles, Alfredo. (2017). La interpretación jurídica en el litigio estratégico en defensa de los derechos humanos en Colombia. Justicia, (32), 227-242. https://dx.doi.org/10.17081/just.22.32.2915

Plan Nacional de Desarrollo 2014-2018 ‘Todos por un nuevo país

Registro Único de Víctimas (RUV) | RNI - Red Nacional de Información

Rettberg Angelika. Construcción de paz en Colombia: contexto y balance. En Construcción de paz en Colombia, comp.. Bogotá: Ediciones Uniandes.

Rettberg, Angelika. 2003. Diseñar el futuro: una revisión de los dilemas de la construcción de paz para el post conflicto. Revista de Estudios Sociales 15: 15-28. Rettberg, Angelika. 2012.

Ricardo Córdova Macías, El Salvador en transición: el proceso de paz, las elecciones generales y los retos de la Gobernabilidad democrática. Ponencia presentada en el IX Congreso de Centroamericano de Sociología. San salvador, Julio de 1994. Publicada en la revista virtual http://revistas.usal.es/index.php/1130-2887/article/view/2337/2386

Rodríguez-Burgos, Karla, Martínez Cárdenas, Alán Alejandro, \& Rodríguez-Serpa, Ferney Asdrual. (2017). Estudio empírico sobre los valores democráticos de 
tolerancia y respeto en la generación milenaria. Justicia, (31), 135-150. https://dx.doi.org/10.17081/just.22.31.2603

Sanabria, Fabián. (2016). Estado, instituciones democráticas y postconflicto en Colombia*. Justicia, (30), 86-95. https://dx.doi.org/10.17081/just.21.30.1351

Sartori, Giovanni, Teoría de la Democracia (1978), Alianza, México, 1989 (2 vols.).

Schmitter, Philippe y Gerhard Lehmbruch, Neocorporativismo. Más allá del Estado y el Mercado, Alianza, México, 1992.

Selwyn Ryan; Gobernabilidad y Desarrollo Democrático en América Latina y el Caribe. Nueva York, USA. Editor PNUD, 1997 (actualizado en 2004). Tomado de: http://www.iidh-jurisprudencia.ac.cr/cedoc/content/13915

Thorstein Veblen. La teoría de la clase ociosa. Alianza Editorial, Madrid, España. 2008.

Zolo, Danilo, La Democracia Difícil (1989), Alianza, México, 1994. 